\title{
Michele Palieri üzüm çeşidinde farklı zamanlarda yapılan yaprak alma ve salkım seyreltme uygulamalarının salkım özellikleri üzerine etkilerinin belirlenmesi
}

Determination of the effects of leaf removal and cluster thinning applications at different times in cv. Michele Palieri on cluster properties

\section{ilknur KORKUTAL ${ }^{1 \mathscr{P}}$ (D) , Elman BAHAR ${ }^{2}$ (D) Serhan AZSÖZ ${ }^{3}$ (D)}

${ }^{1}$ Tekirdağ Namık Kemal University, Faculty of Agriculture, Department of Horticulture, Tekirdağ, Turkey.

${ }^{2}$ Tekirdağ Namık Kemal University, Faculty of Agriculture, Department of Horticulture, Tekirdağ, Turkey.

${ }^{3}$ Silivri Private TURAM Vocational and Technical Anatolian High School, Silivri-Istanbul, Turkey.

\section{MAKALE BILGISI / ARTICLE INFO}

\section{Makale tarihçesi / Article history:}

DOI: $10.37908 /$ mkutbd.908853

Geliş tarihi /Received:02.04.2021

Kabul tarihi/Accepted:22.05.2021

\section{Keywords:}

cv. Michele Palieri, leaf removal, cluster thinning, table grapes, cluster characteristics.

Corresponding author: Illknur KORKUTAL

$\bowtie$ : ikorkutal@nku.edu.tr

\section{Ö Z E T / A B S TR A C T}

Atıf / Citation: Korkutal I, Bahar E, Azsöz S (2021) Michele Palieri üzüm çeşidinde farklı zamanlarda yapılan yaprak alma ve salkım seyreltme uygulamalarının salkım özellikleri üzerine etkilerinin belirlenmesi. MKU. Tar. Bil. Derg. 26(2) : 376-386. DOI: 10.37908/mkutbd.908853

\section{Giriş}

Bağda ürün miktarı ve kalitesini belirlemede salkım ağırlığı ve doğrudan güneşlenen yaprak alanı arasında denge kurulması gerekliliği bilinen bir gerçektir (Reynolds ve ark., 1994; Reeve ve ark., 2018). Taç yönetimi, üzüm verim ve kalitesini iyileştirmek için güneşlenmeyi (Vogel ve ark., 2020), fotosentez kapasitesini ve salkım mikroklimasını optimize etmek amacıyla oluşturulmuş uygulamalardır (Smart ve ark., 1990). Yaprak alma, koltuk alma, uç alma ve tepe alma gibi uygulamalar ile taç içerisinde kalan yaprak ve salkımların havalanmasını artırma, güneş ışınlarının etkisiyle fotosentez faaliyetlerinin artması ve salkımların iyi olgunlaşması teşvik edilmektedir (Smart ve Robinson, 2006; Çelik ve ark., 1998).

Bağcılıkta salkım bölgesindeki yaprakları alma işlemi, ertesi yıl sürecek olan kışlık gözlerin gelişmesini teşvik etmek, tane tutumu sonrası salkımların daha iyi güneş görmesini sağlamak, özellikle renkli üzüm çeşitlerinde renk oluşumu ile birlikte kalite özelliklerini olumlu şekilde artırmaktadır (Dami ve ark., 2005). Trakya Illkeren 
üzüm çeşidinde 10 gün arayla 7 kez ortalama 2 adet yaprak almanın; salkım ağırlığı ve salkım boyunu artırdığı belirlenmiştir (Köse ve ark., 2018). Karaerik üzüm çeşidinde çiçeklenme öncesi, tam çiçeklenme ve tane tutumunda yaprak almanın; kontrole göre salkım eniboyu ve salkım ağırlığını artırdığı, verim ve salkım sıklığını ise azalttığı görülmüştür (Kaya, 2019). Sauvignon Blanc üzüm çeşidinde, tam çiçeklenme, tane tutumu ve iri koruk dönemlerinde sürgünün dibinden itibaren ilk 6 yaprağın alındığı araştırmada; yaprak alma ile tane sayısı, tane iriliği ve verimin azaldığı bildirilmiştir (Beslic ve ark., 2016). Doral üzüm çeşidinde tam çiçeklenme zamanında yapılan; sürgün dibindeki ilk 6 yaprak+koltuk sürgünü alma uygulamasının, ürün yükü dengelemek amacıyla, salkım seyreltmeye uygulamalarına alternatif olabileceği ileri sürülmüştür (Verdenal ve ark., 2016).

Salkım seyreltme ile omca üzerinde ürün yükü azaltılarak daha kaliteli üzüm almak mümkündür (Basile ve ark., 2018). Salkım seyreltme; olgunlaşmadan önce salkım veya çiçekleri baskılama olarak da tanımlanmaktadır (Palliotti ve Cartechini, 2000). Omcaların az salkıma sahip olmaları özümlemeyi iyileştirerek kaliteyi artırabilmektedir. Bu şekilde salkım seyreltme; üretim merkezi/tüketim merkezi oranına doğrudan etki yapmaktadır (Reynolds ve ark., 1994). Salkım seyreltme; salkımların arasına ve taç içerisine daha fazla hava ve güneş ışığının girişini sağlamakta ve taç içindeki koşulları iyileştirmektedir (Smithyman ve ark., 1998). Seyreltmenin yapıldığı dönem veya oranı istenilen amaca ulaşmak için düzenlenebilmektedir (Dumartin ve ark., 1990; Pita, 2006; Martins, 2007; Mawdsley ve ark., 2019).

Tokat ilinde yetiştirilen Narince üzüm çeşidinde salkım seyreltme uygulamasının verimde azalmaya neden olduğu, ancak salkım seyreltme uygulamalarının kontrole göre salkım ağırlığını artırdığı belirlenmiştir. Yapılan \%30 salkım seyreltme uygulamasının ise salkım özelliklerini olumlu etkilediği tespit edilmiştir (Bekar ve Cangi, 2018). Erken dönem yapılan yaprak alma ve salkım seyreltme ve bunların kombinasyonlarının; Vranac ve Cabernet-Sauvignon çeşitlerinde salkım ağırlığı, salkımdaki tane sayısı ve verimi düşürdüğü bulunmuştur (Bogicevic ve ark., 2015). Pinot Noir (Klon 115) üzüm çeşidinde farklı zamanlarda yapılan salkım seyreltme uygulamalarının, verimde azalmaya neden olduğu Mawdsley ve ark. (2019) tarafından belirlenmiştir. Salkım seyreltme ve yaprak alma uygulamalarının verim özelliklerinin yanısıra kalite özellikleri üzerinde olumlu etkilere sahip olduğu, kırmızı-siyah üzüm çeşitlerinden Beauty Seedless ve Tekirdağ Çekirdeksizi üzüm çeşitlerinde tane tutumu ve ben düşme dönemlerinde $\% 30$ oranında kontrollü bir salkım seyreltme sonucunda toplam antosiyanin ve tane kabuk renginde homojen renk elde etme üzerinde etkili olduğu bildirilmiştir (Cantürk ve Kunter, 2018).

$\mathrm{Bu}$ araştırmada Michele Palieri üzüm çeşidinde farklı zamanlarda yapılan yaprak alma ve salkım seyreltme uygulamalarının salkım özellikleri üzerine etkileri belirlenmiştir.

\section{MATERYAL ve YÖNTEM}

\section{Materyal}

Çalışma 2018-2019 ve 2019-2020 vejetasyon periyodlarında iki yıl süreyle Michele Palieri/110R aşı kombinasyonundan oluşan bağda yürütülmüştür. Denemenin yürütüldüğü bağ Tekirdağ ili, Karaevli Mahallesi sınırları içinde $41^{\circ} 01^{\prime} 11.41^{\prime \prime} \mathrm{K}$ enlem ve $27^{\circ}$ 39' 49.14" D boylam koordinatlarında yer almaktadır. Omcalar on yaşında, $2.5 \times 1.5 \mathrm{~m}$ sıra arası ve sıra üzeri mesafede dikilmiş, gövde yüksekliği $160 \mathrm{~cm}$, büyük T şekli verilmiş ve T genişliği $170 \mathrm{~cm}$ 'dir.

\section{iklim verileri ve fenolojik gelişme aşamaları}

Her iki vejetasyon süresi (2018-2019 ve 2019-2020) boyunca iklim verileri alınmış (TMM, 2019) ve fenolojik gelişme aşamaları (Lorenz ve ark., 1995) kaydedilmiştir (Çizelge 1).

Tekirdağ'da 2018 yılı ortalama sıcaklığı $15.53^{\circ} \mathrm{C}$ ve 2019 yılı ortalama sıcaklığı ise $15.61^{\circ} \mathrm{C}$ 'dir. Bu değer uzun yıllar ortalaması $14.08^{\circ} \mathrm{C}$ 'nin yaklaşık olarak $1.5^{\circ} \mathrm{C}^{\prime}$ nin üstündedir. 2018 yılı için ortalama oransal nem \%76.26 ve 2019 da ise \%70.49'dur. Yıllık toplam yağış miktarı sırasıyla; $675.00 \mathrm{~mm}$ ve $334.60 \mathrm{~mm}$ olarak tespit edilmiştir. Uzun yıllar yağış ortalaması 589.10 mm'dir. 2018 yılı uzun yıllar yağıs ortalamasından $85.90 \mathrm{~mm}$ fazla, 2019 yılı ortalamasının da 340.4 mm eksik olduğu görülmüştür. Vejetasyon döneminde güneşlenme süresi 2018 yılı için 1359.6 saat ve 2019 yılında ise 1540.1 saattir.

Araştırmada Tane Tutumu (EL 27): 06.06.2018 ve 15.06.2019 tarihinde; İri Koruk (EL 31): 26.06.2018 ve 05.07.2019 tarihinde ve Ben Düşme (EL 35): 25.07.2018 ve 03.08.2019 tarihinde gerçekleşmiştir.

\section{Yöntem}

Çalışmada üç farklı fenolojik dönemde, biri kontrol olmak üzere dört faklı yaprak alma ve salkım seyreltme uygulaması yapılmıştır. Uygulama zamanları [Tane Tutumu (TT), İri Koruk (IK) ve Ben Düşme (BD)]; her alt parselde de bir yaprak alma ve salkım seyreltme olarak Kontrol=U1, U2, U3 ve U4 olarak sıralanmıştır. Sürgünler $100-120 \mathrm{~cm}$ iken omca başına 22-24 sürgün ve 30-35 salkım kalacak şekilde dengelenerek sürgünler gelişmeye 
bırakılmıştır. Kenar etkileri göz ardı edildikten sonra denemede homojen oldukları kabul edilen toplam 72 omca kullanılmıştır. Yaprak alma ve salkım seyreltme uygulamaları aşağıdaki şekilde düzenlenmiştir:

(U1) (Kontrol=Yaprak Alma Yok + Salkım Seyreltme Yok): Farklı zamanlarda yapılacak olan yaprak alma ve salkım seyreltme işlemleri uygulanmamış; salkımlar hasada kadar muhafaza edilmiştir.

(U2) (Yaprak Alma Yok + Salkım Seyreltme): Yaprak alma işlemleri uygulanmamıştır. Tane tutumu, iri koruk ve ben düşme dönemlerinde, salkımların $\% 50$ 'si alınmış ve hasada kadar beklenmiştir.

(U3) (Yaprak Alma + Salkım Seyreltme Yok): Tane tutumu, iri koruk ve ben düşme dönemlerinde koltuk sürgünlerinin ilk 3-4 yaprağı ve ilk salkıma kadar olan ana yapraklar tamamen alınmıştır. Salkımlar hasada kadar omca üzerinde bekletilmişlerdir.

(U4) (Yaprak Alma + Salkım Seyreltme): Tane tutumu, iri koruk ve ben düşme dönemlerinde koltuk sürgünlerinin ilk 3-4 yaprağı ve ilk salkıma kadar olan ana yapraklar alınmış; var olan salkımların \%50'si alınmıştır.

Uygulama zamanları aşağıda verilmiştir:

Tane Tutumu: Tane tutumunun $\% 50$ olarak görülmesi Iri Koruk: Salkımların \%50'sinin iri koruk halini alması, Ben Düşme: Salkımdaki tanelerin $\% 50$ 'sinde ben düşmenin görülmesi, halinde gerçekleştirilmiştir.

Çizelge 1. 2018 ve 2019 yıllarına ait iklim verileri (TMM, 2019)

Table 1. Climatical data of 2018 and 2019 (TMM, 2019)

\begin{tabular}{lcccccccc}
\hline & \multicolumn{7}{c}{ Yıllar } \\
\cline { 2 - 8 } Aylar & 2018 & 2019 & 2018 & 2019 & 2018 & 2019 & 2018 & 2019 \\
\cline { 2 - 8 } & \multicolumn{2}{l}{ Ortalama Sıcaklık ( ${ }^{\circ} \mathrm{C}$ ) } & \multicolumn{2}{c}{ Ortalama Nispi Nem (\%) } & Ortalama Yağış (mm) & $\begin{array}{c}\text { Toplam Güneşlenme } \\
\text { Süresi (saat) }\end{array}$ \\
\hline Ocak & 6.6 & 5.6 & 85.6 & 76.3 & 76.4 & 63.8 & 101.2 & 55.1 \\
Şubat & 7.3 & 5.8 & 86.1 & 74.3 & 95.3 & 44.8 & 49.0 & 113.5 \\
Mart & 9.8 & 9.3 & 85.8 & 70.8 & 76.8 & 30.2 & 92.0 & 210.9 \\
Nisan & 14.0 & 11.6 & 76.4 & 71.9 & 10.6 & 42.9 & 240.3 & 177.7 \\
Mayıs & 18.5 & 17.9 & 79.2 & 70.5 & 27.5 & 31.2 & 183.7 & 191.7 \\
Haziran & 22.3 & 24.1 & 72.6 & 64.8 & 75.4 & 7.5 & 199.1 & 237.1 \\
Temmuz & 25.1 & 23.9 & 69.5 & 65.0 & 82.7 & 18.7 & 259.5 & 278.9 \\
Ağustos & 26.0 & 25.3 & 63.1 & 62.7 & 0.0 & 0.0 & 228.4 & 279.9 \\
Eylül & 21.8 & 21.6 & 67.8 & 65.1 & 18.7 & 9.6 & 132.8 & 209.8 \\
Ekim & 16.7 & 17.5 & 76.0 & 73.3 & 48.2 & 46.2 & 125.8 & 175.0 \\
Kasım & 12.1 & 15.5 & 76.7 & 75.7 & 48.2 & 17.4 & 52.5 & 123.0 \\
Aralık & 6.2 & 9.2 & 76.3 & 75.5 & 115.2 & 22.3 & 59.9 & 71.1 \\
\hline
\end{tabular}

\section{Araştırmada incelenen kriterler}

Hasatta, salkım özelliklerini belirlemek için her uygulamadan alınan 5'er salkımda ölçümler gerçekleştirilmiştir. Salkım eni ve boyu $(\mathrm{cm})$, salkım ağırlığı $(\mathrm{g})=$ [omca başına verim/salkım sayısı], salkım hacmi $\left(\mathrm{cm}^{3}\right)$, salkımdaki tane sayısı (adet),

Salkım sıklığı=Salkım hacmi $\left(\mathrm{cm}^{3}\right) /[($ Salkımdaki tane sayısıxTane hacmi $\left(\mathrm{cm}^{3}\right)$ ] formülünden hesaplanmıştır. Elde edilen rakam 1'den küçük ise salkım sık, eşit veya büyük ise salkım seyrek olarak değerlendirilmiştir (OIV, 2009). Birinci sınıf salkım oranı ve sıklığı (\%): Hasat zamanında dekardan elde edilen birinci sınıf (renk, aroma bakımından yeterli olgunluğa ulaşmış, albenisi yüksek, yara bere ve çürük içermeyen salkımlar) olarak belirlenmiş ve ayrıca salkım sıklığı kaydedilmiştir. Benzer şekilde ikinci sınıf salkım oranı (\%) belirlenmiştir. Ayrıca her omca hasat zamanında ayrı ayrı hasat edilmiş ve omca başına verim $\mathrm{kg}$ omca $^{-1}$ olarak hesaplanmıştır.

\section{Deneme deseni ve istatistik analiz}

Deneme, Tesadüf Blokları deneme desenine göre 3 tekerrürlü olarak kurulmuştur. Her bir parsel bir uygulama zamanını oluşturmuştur. Her iki yılda elde edilen veriler JUMP istatistiki programı ile değerlenmeye tabi tutulmuştur. Uygulamalar arasındaki istatistiki farklılıkları ortaya koymak amacıyla LSD testi kullanılmıştır.

\section{BULGULAR ve TARTIŞMA}

\section{Salkım eni $(\mathrm{cm})$}

Salkım eni üzerine uygulamalar ve uygulama dönemlerinin etkisi incelendiğinde DT (Dönem Ana 
Etkisi) ve UT (Uygulama Ana Etkisi) interaksiyonlarının istatistiki olarak $p<0.05$ seviyesinde önemli, YT (Yll Ana Etkisi)'nin ise istatistiki olarak önemsiz olduğu görülmüştür (Şekil 1). DT bakımından IK $(13.98 \mathrm{~cm})$ dönemi birinci önem grubunda, BD $(12.97 \mathrm{~cm})$ döneminin ise son önem grubunda yer aldığı kaydedilmiştir. UT incelendiğinde istatistiki olarak ( $p$ $<0.05$ ) önemli olup, birinci önem grubunda U2 (14.41 $\mathrm{cm})$ uygulamasının ve son önem grubunda ise U3 (11.72 $\mathrm{cm}$ ) uygulamasının yer aldığı tespit edilmiştir. YT'ne göre istatistiki olarak önemsiz olup rakamsal olarak yüksek değer 2018 yılından $(13.57 \mathrm{~cm})$ alınmıştır.

Ilgaz ve Çelik (2020) Şiraz çeşidinde yaprak alma ve salkım seyreltmenin salkım enine önemli etkisinin olmadığını kaydetmişlerdir. Kaya (2019), Karaerik çeşidinde çiçeklenme öncesi, tam çiçeklenme ve tane tutumu dönemlerinde yaprak almanın salkım enini artırdığını belirlemiştir. Bu çalışmada U2 uygulamasının (yaprak alma yok + salkım seyreltme) salkım eni üzerine olumlu etki yaptığı görülmüştür. Ayrıca İK döneminin de salkım enini artış yönünde etkilediği belirlenmiştir.

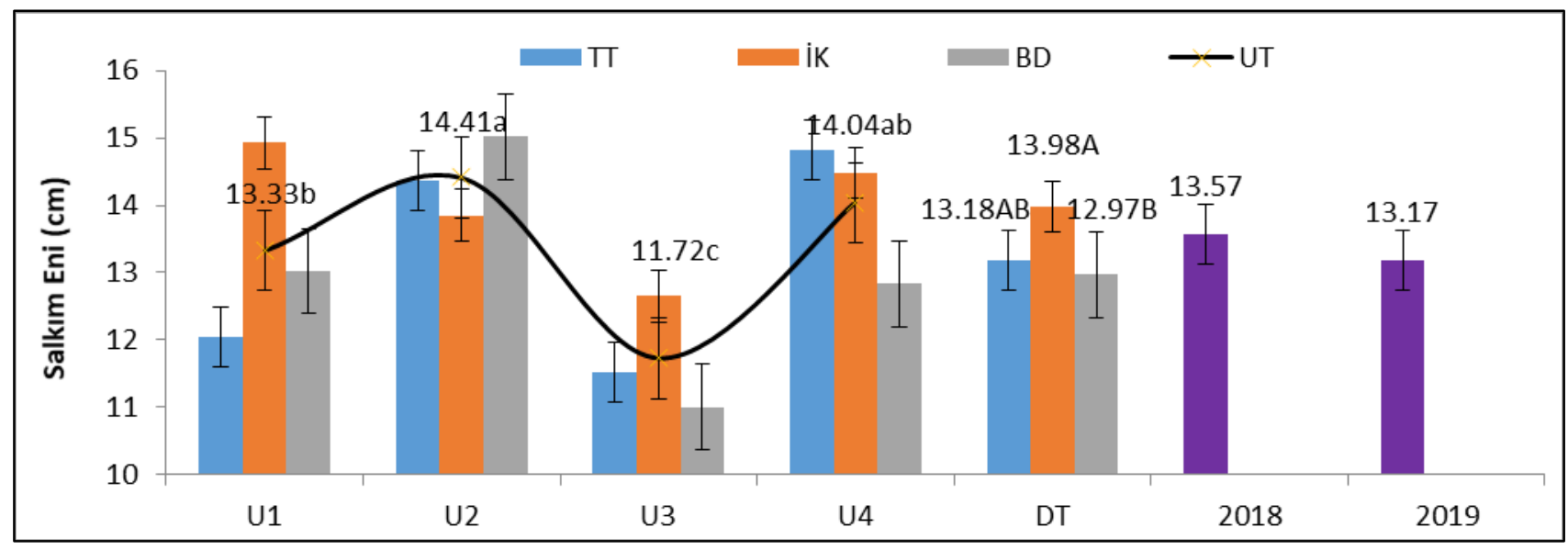

Şekil 1. Uygulamaların ve zamanlarının salkım eni $(\mathrm{cm})$ üzerine etkisi

Figure 1. Applications and times effects on cluster width $(\mathrm{cm})$

$\mathrm{TT}=$ Tane Tutumu, IK= Iri Koruk, BD= Ben Düşme, UT= Uygulama Ana Etkisi, DT= Dönem Ana Etkisi, YT= Yıl Ana Etkisi

DT $p<0.05=0.87$ (Büyük harfle yazılmışır), UT $p<0.05=1.05$ (Küçük harfle yazıımıştır)

\section{Salkım boyu (cm)}

Araştırmada salkım boyu üzerine UT'nin $p<0.05$ 'e göre önemli olduğu belirlenmiştir. Diğer uygulama ve ana etkiler istatistiki açıdan $\mathrm{p}<0.05$ seviyesinde önemsiz olarak kaydedilmiştir (Şekil 2). Salkım boyu açısından UT incelendiğinde; U4 uygulaması $(24.98 \mathrm{~cm})$ birinci önem grubunda yer almıştır. Bunu ikinci önem grubunda U2 ve U3 $(24.03 \mathrm{~cm})$ uygulamaları izlemiştir. Kontrol $(23.23 \mathrm{~cm})$ uygulamasının en son grupta olduğu tespit edilmiştir. YT incelendiğinde 2019 yılında salkımların ortalama 24.58 $\mathrm{cm}$ ve 2018 yllında $23.54 \mathrm{~cm}$ boyunda oldukları belirlenmiştir. DT açısından ise IK döneminin $(24.53 \mathrm{~cm})$ en yüksek rakamsal değerde, BD döneminin $(23.48 \mathrm{~cm})$ en düşük rakamsal değerde olduğu, $\Pi$ döneminin (24.19 $\mathrm{cm}$ ) ise bu iki değer arasında yer aldığı görülmüştür.

Ilgaz ve Çelik (2020), yaprak alma uygulamasının salkım eni üzerine istatistiki olarak etkide bulunmadı̆̆ını, ancak salkım seyreltmenin artış yönünde etki yaptığını Şiraz çeşidi için belirlemişlerdir. Köse ve ark. (2018) Trakya İlkeren çeşidinde; Kaya (2019) Karaerik çeşidinde yaprak alma uygulamalarının salkım boyunu artırdığı bulgusuna erişmişlerdir. Bu araştırmada her iki araştırıcıya paralel şekilde yaprak alma + salkım seyreltme uygulaması (U4) salkım enini artırıcı etkide bulunmuştur.

\section{Salkım ağırlığı (g)}

Araştırmada salkım ağırlı̆ı̆ değerleri incelendiğinde YT, UT, DT interaksiyonlarının istatistiki olarak $(p<0.05)$ önemli olduğu kaydedilmiştir (Çizelge 2). YT incelendiğinde 2018 yılı (557.39 g) ilk önem grubunda, 2019 yılının (471.97 g) son önem grubunda olduğu bulunmuştur. DT incelendiğinde BD (553.18 g) dönemi en yüksek değeri alıp birinci önem grubunda, İK (505.58 g) ve TT $(485.3 \mathrm{~g})$ dönemlerinin aynı önem grubunda oldukları görülmüştür. UT bakımından U2 (581.49 g) birinci, U1 (502.87 g) ikinci ve U4 (499.85 g) ile U3 (474.55 g) üçüncü önem grubunda yer almışlardır. 


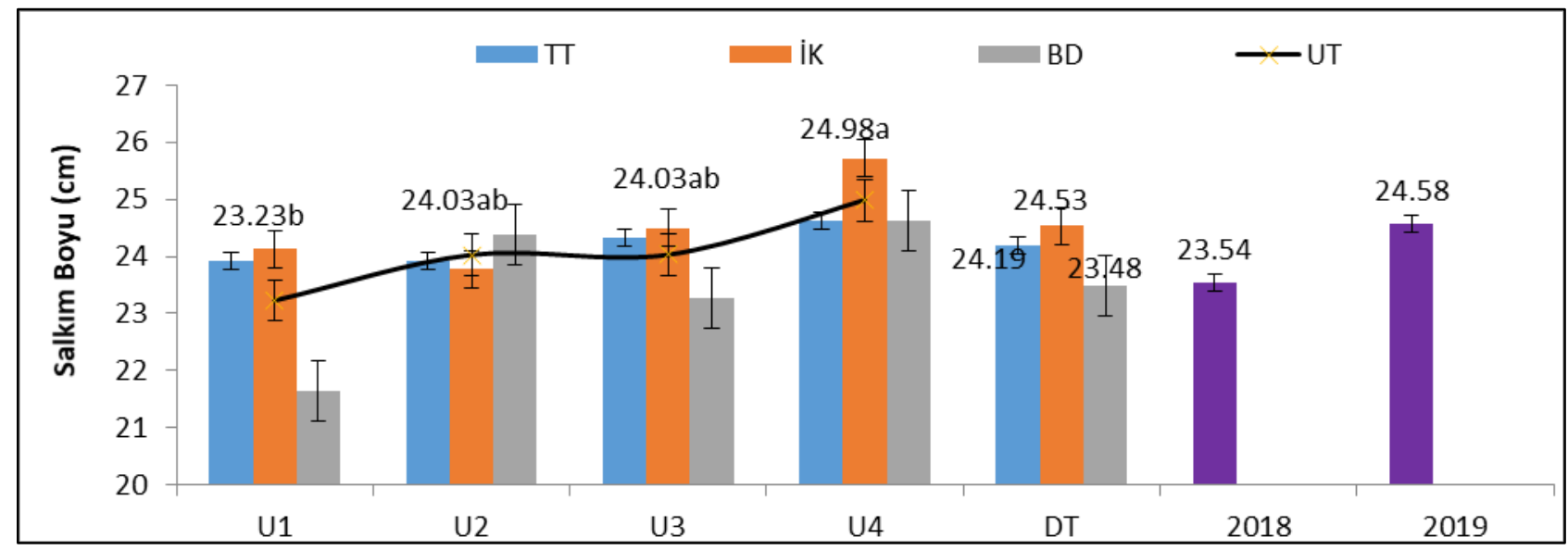

Şekil 2. Uygulamaların ve zamanlarının salkım boyu $(\mathrm{cm})$ üzerine etkisi

Figure 2. Applications and times effects on cluster length $(\mathrm{cm})$

UT $p<0.05=1.73$ (Küçük harfle yazılmıştır)

Çizelge 2. Uygulamalar ve zamanlarının salkım ağırı̆̆ı üzerine etkisi (g)

Table 2. Applications and times effects on cluster weight $(g)$

\begin{tabular}{|c|c|c|c|c|c|c|c|c|}
\hline \multirow{2}{*}{$\begin{array}{l}\text { Uygulama } \\
\text { Zamanları }\end{array}$} & \multirow{2}{*}{ Yillar } & \multicolumn{4}{|c|}{ Uygulamalar } & \multicolumn{3}{|c|}{ Ana Etkiler } \\
\hline & & U1 & U2 & U3 & U4 & DT & \multicolumn{2}{|c|}{ YT } \\
\hline \multirow{3}{*}{$\pi$} & 2018 & 441.99 & 511.90 & 378.97 & 521.62 & \multirow{3}{*}{$485.3 \mathrm{~b}$} & \multirow{9}{*}{$\begin{array}{c}557.39 \mathrm{~A} \\
(2018)\end{array}$} & \multirow{9}{*}{$\begin{array}{c}471.97 \text { B } \\
\text { (2019) }\end{array}$} \\
\hline & 2019 & 452.58 & 510.67 & 567.70 & 496.98 & & & \\
\hline & Yıl Ort. & 447.29 & 511.29 & 473.34 & 509.30 & & & \\
\hline \multirow{3}{*}{ İK } & 2018 & 700.68 & 612.94 & 392.55 & 460.99 & \multirow{3}{*}{$505.58 b$} & & \\
\hline & 2019 & 452.53 & 548.23 & 490.75 & 385.97 & & & \\
\hline & Yıl Ort. & 576.61 & 580.59 & 441.65 & 423.48 & & & \\
\hline \multirow{3}{*}{ BD } & 2018 & 572.26 & 777.30 & 614.13 & 703.45 & \multirow{3}{*}{553.18 a } & & \\
\hline & 2019 & 397.13 & 527.87 & 403.18 & 430.08 & & & \\
\hline & Yıl Ort. & 484.70 & 652.58 & 508.66 & 566.77 & & & \\
\hline UT & & $502.87 A B$ & $581.49 A$ & $474.55 B$ & $499.85 B$ & & & \\
\hline
\end{tabular}

$\mathrm{TT}=$ Tane Tutumu, IK= İri Koruk, BD= Ben Düşme, UT= Uygulama Ana Etkisi, DT= Dönem Ana Etkisi, YT= Yıl Ana Etkisi

YT $p<0.05=35.16$ (Büyük harfle yazıımıştır). DT $p<0.05=43.07$ (Küçük harfle yazıımıştır). UT $p<0.05=80.77$ (Büyük harfle italik yazılmıştır)

Cabernet-Sauvignon üzüm çeşidinde yaprak alma uygulamalarının salkımı irileştirdiği (Bahar ve ark., 2018); Cabernet-Sauvignon ve Pinot Noir üzüm çeşitlerinde uygulanan salkım seyreltmenin salkım ağırlığında olumlu etki yaptığı görülmüştür (Canon ve ark., 2014). Şiraz üzüm çeşidinde salkım ağırlığının salkım seyreltme uygulaması ile arttığı, yaprak alma uygulaması ile değişmediği llgaz ve Çelik (2020) tarafından kaydedilmiştir. Köse ve ark. (2018) Trakya ilkeren çeşidinde; Kaya (2019) Karaerik çeşidinde yaprak alma uygulamalarının salkım ağırlığını artırdığı bulgusuna erişmişlerdir. Ayrıca Basile ve ark. (2018) tarafından Sugrathirteen ${ }^{\circledast}$ çeşidinde $\% 50$ salkım seyreltmenin diğer uygulamalarla karşılaştırıldığında salkım ağılığına istatistiki olarak önemli etkide bulunmadığı kaydedilmiştir. Öte yandan Narince çeşidinde salkım seyreltmenin kontrole nazaran salkım ağırlığını artırdığı saptanmıştır (Bekar ve Cangi, 2018). Ayrıca CabernetSauvignon ve Vranac çeşitlerinde, birlikte ve tek tek uygulanan salkım seyreltme ve yaprak alma uygulamaları kontrole nazaran salkım ağırlığını azaltıcı etkide bulunmuştur (Bogicevic ve ark., 2015). Yapılan çalışmada da U2 uygulamasının (yaprak alma yok + salkım seyreltme) salkım ağırlığını artırdığı belirlenmiştir.

\section{Salkım hacmi $\left(\mathrm{cm}^{3}\right)$}

Araştırmada salkım hacmi üzerine YT istatistiki olarak önemsiz bulunmuştur. DT ve UT interaksiyonlarının istatistiki olarak ( $p<0.05$ seviyesinde) önemli olduğu kaydedilmiştir (Şekil 3). YT istatistiki olarak önemsiz olup, 2018 yılı $361.30 \mathrm{~cm}^{3}$ değerini, 2019 yılı $333.08 \mathrm{~cm}^{3}$ salkım hacmi değerini almıştır. UT bakımından en yüksek salkım 
hacmi değerinin $\left(418.25 \mathrm{~cm}^{3}\right)$ U2 uygulamasından ve en düşük değerin ise U3 $\left(256.22 \mathrm{~cm}^{3}\right)$ uygulamasından elde edildiği görülmüştür.

DT açısından incelendiğinde ise; í dönemi $\left(379.46 \mathrm{~cm}^{3}\right)$ en yüksek değerde ve birinci önem grubunda; sırasıyla diğer önem gruplarında ise $\Pi T\left(355.98 \mathrm{~cm}^{3}\right)$ ve $B D$ dönemlerinin $\left(306.15 \mathrm{~cm}^{3}\right)$ yer aldığı bulunmuştur. Korkutal ve ark. (2017), Syrah üzüm çeşidinde ben düşme döneminde yapılan yaprak alma uygulamalarının salkım özelliklerini belirgin şekilde etkilemediğini belirttikleri bulgusu ile benzerlik görülmüştür.

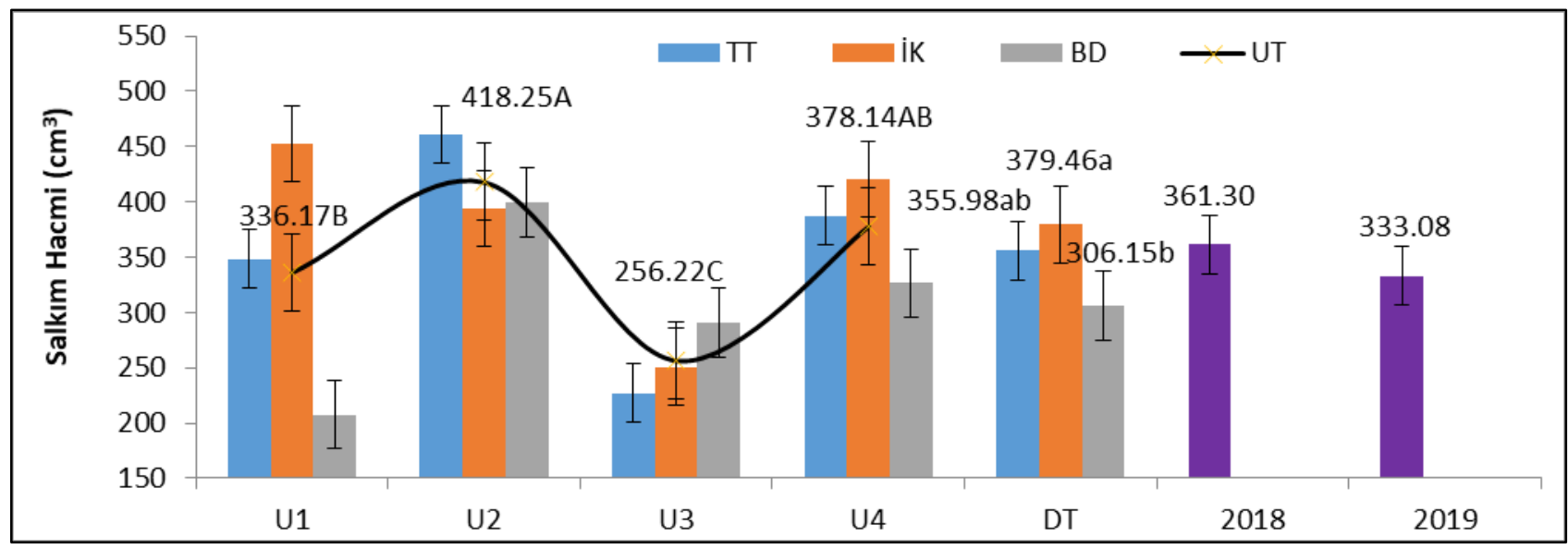

Şekil 3. Uygulamaların ve zamanlarının salkım hacmi $\left(\mathrm{cm}^{3}\right)$ üzerine etkisi

Figure 3. Applications and times effects on cluster volume $\left(\mathrm{cm}^{3}\right)$

DT $p<0.05=50.96$ (Küçük harfle yazılmıştır), UT $p<0.05=76.76$ (Büyük harfle yazılmıştır)

\section{Salkımdaki tane sayısı (adet)}

Salkımdaki tane sayısı değerleri incelendiğinde UT ve DT'nin istatistiki olarak ( $p<0.05$ ) önemli olduğu kaydedilmiştir. Yıl ana etkisinin istatistiki olarak önemli olmadığı ve rakamsal olarak 2019 yılının 63.88 adet ve
2018 yılının 63.58 adet salkımdaki tane sayısı değerlerini aldığı ve bu değerlerin birbirine çok yakın olduğu görülmüştür. Buradan; iki yıl boyunca salkımdaki tane sayılarının değişmediği söylenebilir (Çizelge 3).

Çizelge 3. Uygulamalar ve zamanlarının salkımdaki tane sayısı (adet) üzerine etkisi

Table 3. Applications and times effects on berry number on cluster (number)

\begin{tabular}{|c|c|c|c|c|c|c|c|c|}
\hline \multirow{2}{*}{$\begin{array}{l}\text { Uygulama } \\
\text { Dönemleri }\end{array}$} & \multirow{2}{*}{ Yillar } & \multicolumn{4}{|c|}{ Uygulamalar } & \multicolumn{3}{|c|}{ Ana Etkiler } \\
\hline & & U1 & U2 & U3 & U4 & DT & \multicolumn{2}{|c|}{ YT } \\
\hline \multirow{3}{*}{ TT } & 2018 & 60.00 & 63.00 & 61.00 & 62.67 & \multirow{3}{*}{$62.71 \mathrm{AB}$} & \multirow{9}{*}{$\begin{array}{c}63.58 \\
(2018)\end{array}$} & \multirow{9}{*}{$\begin{array}{l}63.88 \\
(2019)\end{array}$} \\
\hline & 2019 & 50.33 & 59.33 & 66.00 & 79.33 & & & \\
\hline & YIl Ort. & 55.17 & 61.17 & 63.50 & 71.00 & & & \\
\hline \multirow{3}{*}{ ik } & 2018 & 82.00 & 80.67 & 50.67 & 69.33 & \multirow{3}{*}{$69.88 \mathrm{~A}$} & & \\
\hline & 2019 & 52.00 & 77.33 & 81.67 & 65.33 & & & \\
\hline & YIl Ort. & 67.00 & 79.00 & 66.17 & 67.33 & & & \\
\hline \multirow{3}{*}{ BD } & 2018 & 52.67 & 64.67 & 55.00 & 61.33 & \multirow{3}{*}{58.63 B } & & \\
\hline & 2019 & 49.33 & 71.00 & 60.33 & 54.67 & & & \\
\hline & YIl Ort. & 51.00 & 67.83 & 57.67 & 58.00 & & & \\
\hline UT & & $57.72 \mathrm{~b}$ & 69.33 a & $62.44 a b$ & $65.44 a b$ & & & \\
\hline
\end{tabular}

UT $p<0.05=8.82$ (Küçük harfle yazılmıştır), DT $p<0.05=10.53$ (Büyük harfle yazılmıştır)

UT bakımından incelendiğinde U2 uygulaması (69.33 adet) en yüksek değeri alırken, Kontrol (U1) uygulamasının ise (57.72 adet) en düşük salkımdaki tane sayısına sahip olduğu görülmüştür. DT incelendiğinde İ döneminin en yüksek değerde (69.88 adet) ve BD döneminde en düşük değerde (58.63 adet) ve TT döneminin (62.71 adet) bu ikisinin arasında yer aldığı bulunmuştur.

Kotseridis ve ark. (2012) Merlot ve Sangiovese üzüm çeşitlerinde yapılan yaprak alma uygulamasında 
salkımdaki tane sayısının azaldığını bulmuşlardır. Beslic ve ark. (2016) TT döneminde yapılan yaprak alma uygulamasının Sauvignon Blanc çeşidinde tane sayısını artırdığını ifade etmişlerdir. Yapılan çalışmada ik döneminin tane sayısını artırdığı belirlenmiştir. Ayrıca U2 uygulamasının (yaprak alma yok + salkım seyreltme) salkımdaki tane sayısını artırdığı bulunmuştur. Araştırıcıların belirttiği şekilde U3 uygulamasının tane sayısı üzerine artırıcı etkide bulunmadığı saptanmıştır. Bunun çeşit kökenli olması söz konusudur.

\section{Salkım sıklığı}

Araştırmada, salkım sıklığı değerleri incelendiğinde
Uygulama ana etkisi ve Dönem ana etkisi'nin $p<0.05$ seviyesinde önemli; Yıl ana etkisinin ise istatistikî olarak önemsiz olduğu bulunmuştur (Şekil 4). UT bakımından U2 (0.86) ve U4 (0.79) uygulamalarının en yüksek değerleri alarak ve aynı önem grubunda yer aldığı, Kontrol'ün (0.76) bunu takip ettiği ve U3 uygulamasının (0.64) son grubu oluşturduğu görülmüştür. DT incelendiğinde iK (0.82) döneminin birinci önem grubunda, TT (0.77) döneminin ikinci önem grubunda ve BD döneminin (0.70) üçüncü önem grubunda olduğu bulunmuştur. Salkımdaki tane sayısı açısından YT önemsiz bulunmuş olup; 2019 yılının 0.79 ve 2018 yılının 0.73 değerinde olduğu tespit edilmiştir.

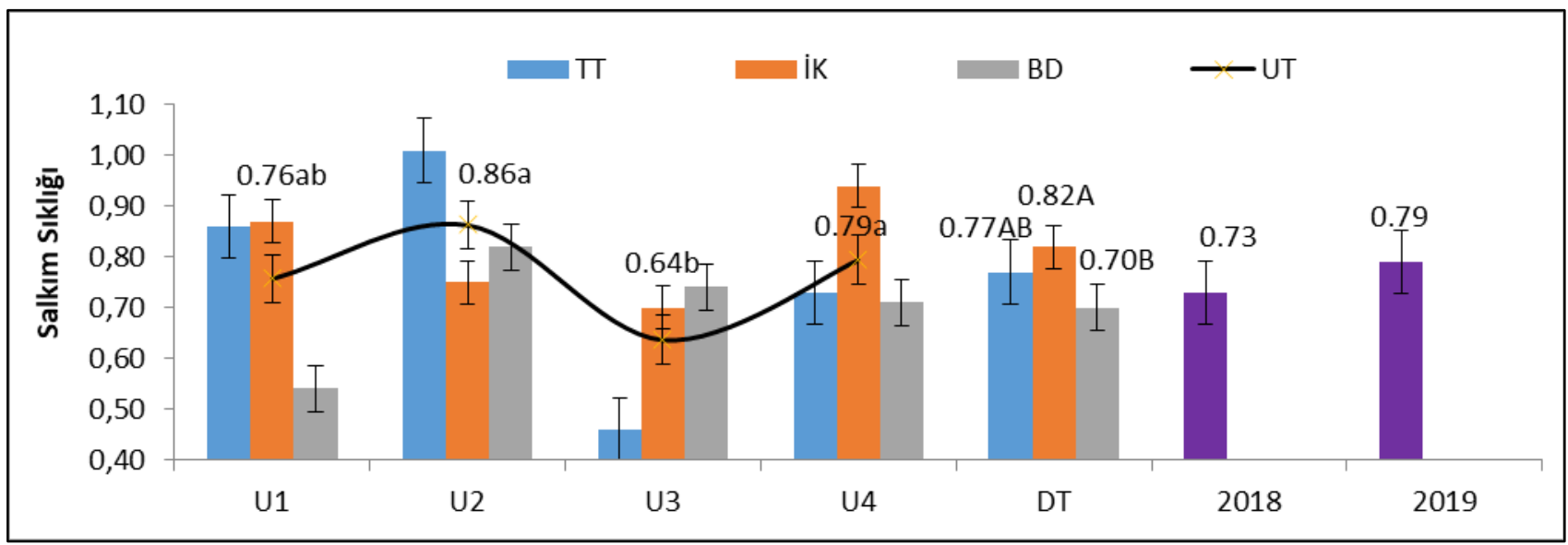

Şekil 4. Uygulamalar ve zamanlarının salkım sıklığı üzerine etkisi

Figure 4. Applications and times effects on cluster compactness

UT $p<0.05=0.21$ (Küçük harfle yazılmıştır), DT $p<0.05=0.378$ (Büyük harfle yazıımıştır)

Yaprak alma uygulamaları sonucunda CabernetSauvignon ve Sangiovese üzüm çeşitlerinde salkım sıklığı artarken; Merlot üzüm çeşidinde yaprak alma şiddetine bağıı olarak salkım sıklığının azaldığı görülmüştür (Kotseridis ve ark., 2012). Karaerik çeşidinde yapılan yaprak almanın salkım sıklığını azalttığı Kaya (2019) tarafından ifade edilmiştir. Ilgaz ve Çelik (2020), yaprak alma ve salkım seyreltme uygulamalarının Şiraz üzüm çeşidinde salkım sıklığı üzerine istatistiki olarak önemli etkide bulunmadığını bildirmişlerdir. Salkım özellikleri açısından değerlendirildiğinde salkım seyreltmenin; salkım özelliklerini diğer uygulamalara kıyasla iyileştirdiği belirlenmiştir. Dönemsel olarak değerlendirildiğinde ise, İri Koruk döneminde yapılan U2 uygulamasının (yaprak alma yok + salkım seyreltme) diğerlerine nazaran daha iyi sonuçlar verdiği görülmüştür.

\section{Birinci sınıf salkım oranı (\%)}

Birinci sınıf salkım oranı açısından YT istatistiki olarak ( $p$ $<0.05$ seviyesinde) önemlidir. UT ve DT'nin istatistiki olarak önemli olmadığı görülmüştür. YT bakımından ilk önem grubunda 2019 yılı (\%83.74) ve son önem grubunda 2018 yılının (\%47.19) yer aldığı saptanmıştır (Şekil 5).

UT bakımından istatistiki olarak önemsiz olmakla birlikte rakamsal olarak; U4 (\%67.74) uygulaması, U2 (\%67.30) uygulaması, U3 (\%64.34) uygulaması ve U1=Kontrol (\%62.51) uygulaması şeklinde sıralandığı tespit edilmiştir. Salkım seyreltme uygulamalarında (U4 ve U2); seyreltme işlemi yapılırken kötü salkımlar seçilip uzaklaştırıldığından, doğal olarak birinci sınıf salkım oranları bu uygulamalarda yükselmiştir.

DT istatistiki olarak önemsiz bulunmuş azalan değerlerle; TT (\%68.37), í (\%64.28) ve BD (\%63.77) dönemleri şeklinde sıralanmıştır. TT döneminde yapılan uygulamaların birinci sınıf salkım oranını artırmada katkı sağladığı görülmüştür.

\section{ikinci sınıf salkım oranı (\%)}

İkinci sınıf salkım oranı incelendiğinde YT istatistiki olarak önemli, UT ve DT istatistiki olarak önemsiz bulunmuştur. İkinci sınıf salkım oranına etkisi bakımından YT 


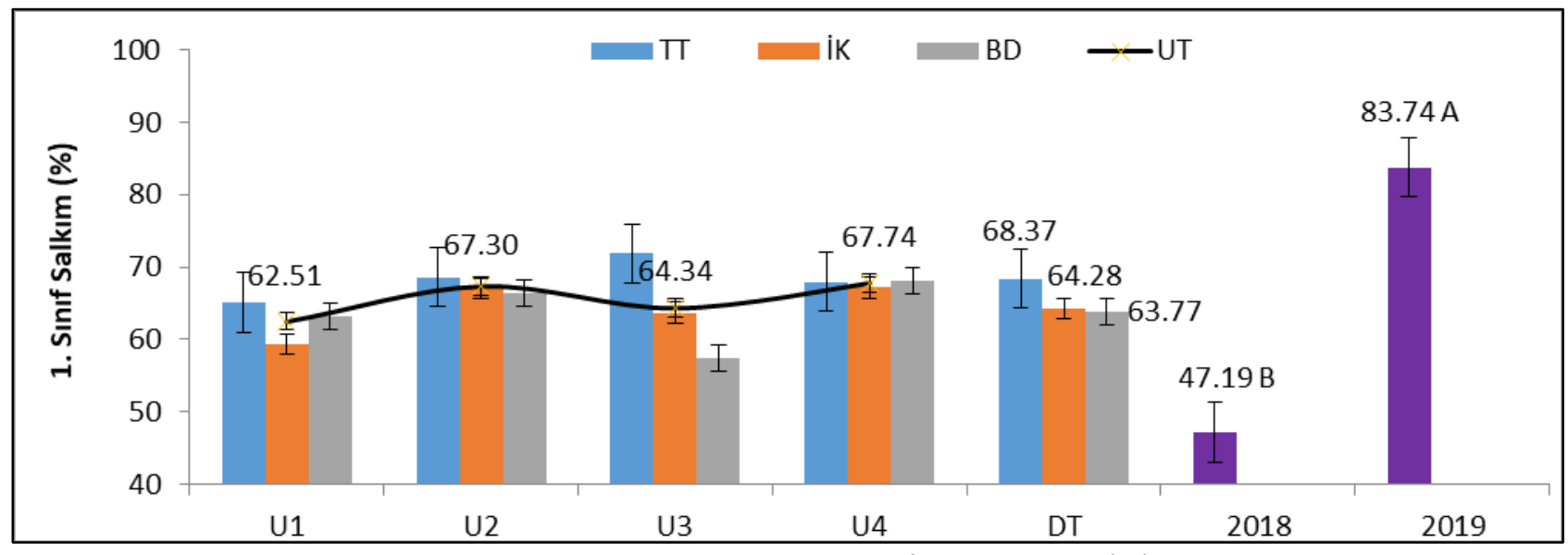

Şekil 5. Uygulamalar ve zamanlarının birinci sınıf salkım oranı (\%) üzerine etkisi

Figure 5. Applications and times effects on first class cluster ratio (\%)

YT $p<0.05=6.53$ (Büyük harfle yazılmıştır)

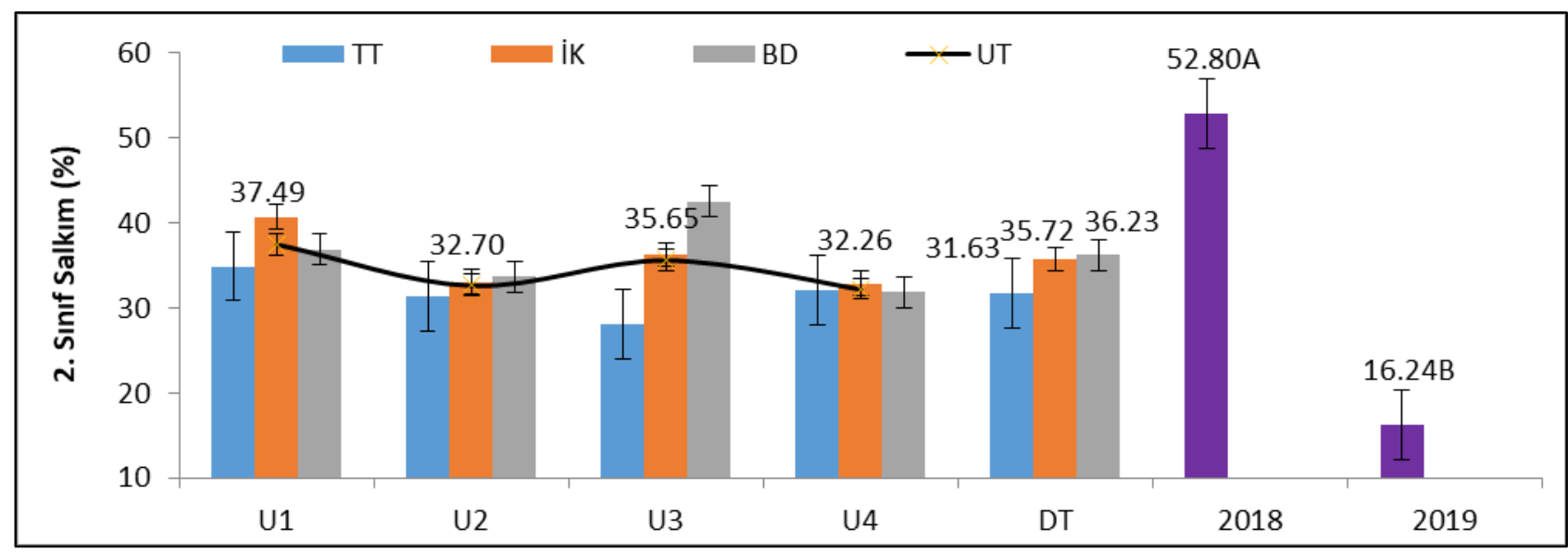

Şekil 6. Uygulamaların ve zamanlarının ikinci sınıf salkım oranı (\%) üzerine etkisi

Figure 6. Applications and times effects on second class cluster ratio (\%)

YT $p<0.05=6.53$ (Büyük harfle yazılmışır)

incelendiğinde; 2018 yılı birinci önem grubunda ve 2019 yılı diğer önem grubunda yer almıştır (Şekil 6).

DT incelendiğinde rakamsal olarak, BD (\%36.23), ik (\%35.72) ve TT (\%31.63) dönemi olarak sıralanmışlardır. TT dönemi istatistiki olarak önemli olmamasına rağmen; burada ikinci sınıf salkım oranını rakamsal olarak azaltan uygulama olarak tespit edilmiştir.

UT incelendiğinde değerlerin U1=Kontrol (\%37.49) - U2 (\%32.70) arasında olduğu belirlenmiştir. Buradan hareketle Uygulama ana etkisi açısından yaprak alma yok + salkım seyreltme uygulamasının (U2) ikinci sınıf salkım oranını istatistiki olarak değil, rakamsal olarak azaltan etki yaptığı belirlenmiştir.

İkinci sınıf salkım oranının yüksek olması, sofralık çeşitlerde istenmeyen bir kriterdir. İkinci sınıf salkım oranının düşük olduğu uygulamalar, salkım seyreltme yapılmış uygulamalardır. Bu da birinci sınıf salkım varlığını rakamsal olarak artırmak için; küçük, yara-bere taşıyan, hastalık belirtisi gösterebilen ve iyi gelişmemiş olan salkımların alınmasının gerekliliğini göstermesi bakımından önemli bir sonuçtur.

\section{Omca başına verim ( $\mathrm{kg} \mathrm{omca}^{-1}$ )}

Yapılan uygulama ve zamanlarının asma başına verim üzerine etkileri incelendiğinde YT ve UT $(p<0.05)$ istatistiki olarak önemli, DT ise önemsiz bulunmuştur (Çizelge 4). Farklı dönem ve farklı uygulamaların YT üzerine etkileri incelendiğinde 2018 yılının birinci önem grubunda; 2019 yılının ise son önem grubunda yer aldığı belirlenmiştir. UT bakımından birinci önem grubunda Kontrol (18.71 kg omca-1) ile U3 (17.66 kg omca-1) uygulamaları yer almıştır. i̇kinci önem grubunda yer alan uygulama $13.66\left(\mathrm{~kg} \mathrm{omca}^{-1}\right)$ değeriyle U2 olmuştur. Son önem grubunda U4 (9.89 kg omca-1) uygulamasının yer aldığı görülmüştür. Son grupta yer alan U4 uygulaması yaprak alma + salkım seyreltme yapılan uygulamadır. Buradaki verim değerinin Kontrol uygulamasının yaklaşık yarısı değerinde olduğu görülmüştür. Kontrol'e nazaran 
U4 uygulamasında $\% 48$, U2 uygulamasında $\% 27$ ve U3 uygulamasında $\% 8$ oranında omca başına verim azalması kaydedilmiştir.

DT incelendiğinde, istatistiki olarak önemsiz olmakla birlikte rakamsal olarak azalan sırada; BD (15.71 kg omca ${ }^{-}$ $\left.{ }^{1}\right)$, iK (15.01 kg omca-1) ve TT (13.93 kg omca-1) dönemi şeklinde gerçekleşmiştir. Diğer yandan BD döneminin en yüksek verimi sağladığı ancak; birinci sınıf salkım oranı bakımından da en son sırada yer aldığı göz ardı edilmemelidir.

Çizelge 4. Uygulamalar ve zamanlarının omca başına verim ( $\left.\mathrm{kg} \mathrm{omca-}{ }^{1}\right)$ üzerine etkisi Table 4. Applications and times effects on yield per vine $\left(\mathrm{kg}^{\mathrm{vine}} \mathrm{e}^{-1}\right)$

\begin{tabular}{|c|c|c|c|c|c|c|c|c|}
\hline \multirow{2}{*}{$\begin{array}{l}\text { Uygulama } \\
\text { Dönemleri }\end{array}$} & \multirow{2}{*}{ Yillar } & \multicolumn{4}{|c|}{ Uygulamalar } & \multicolumn{3}{|c|}{ Ana Etkiler } \\
\hline & & U1 & U2 & U3 & U4 & DT & \multicolumn{2}{|c|}{ YT } \\
\hline \multirow{3}{*}{ TT } & 2018 & 17.22 & 9.77 & 13.95 & 10.62 & \multirow{3}{*}{13.93} & \multirow{9}{*}{$\begin{array}{c}15.95 \mathrm{~A} \\
(2018)\end{array}$} & \multirow{9}{*}{$\begin{array}{c}13.81 \text { B } \\
(2019)\end{array}$} \\
\hline & 2019 & 14.58 & 15.12 & 22.84 & 7.36 & & & \\
\hline & Yıl Ort. & 15.90 & 12.45 & 18.40 & 8.99 & & & \\
\hline \multirow{3}{*}{ İK } & 2018 & 27.55 & 12.47 & 13.47 & 9.98 & & & \\
\hline & 2019 & 15.56 & 16.58 & 17.29 & 7.14 & 15.01 & & \\
\hline & Yıl Ort & 21.55 & 14.53 & 15.38 & 8.56 & & & \\
\hline \multirow{3}{*}{ BD } & 2018 & 22.44 & 16.35 & 23.79 & 13.80 & \multirow{3}{*}{15.71} & & \\
\hline & 2019 & 14.92 & 11.68 & 12.24 & 10.44 & & & \\
\hline & Yıl Ort & 18.68 & 14.02 & 18.02 & 12.12 & & & \\
\hline UT & & $18.71 \mathrm{a}$ & $13.66 \mathrm{~b}$ & $17.26 \mathrm{a}$ & $9.89 \mathrm{c}$ & & & \\
\hline
\end{tabular}

YT $p<0.05=1.47$ (Büyük harfle yazılmıştır), UT $p<0.05=2.68$ (Küçük harfle yazıımıştır)

Merlot ve Cabernet-Sauvignon üzüm çeşitlerinde Tane Tutumu dönemi yapılan yaprak alma uygulamalarının verimde azalmaya sebep olduğu, Sangiovese üzüm çeşidinde ise değişim yaratmadığı (Kotseridis ve ark., 2012); Kekfrankos ve Turan üzüm çeşitlerinde yaprak alma uygulamalarının verim kaybına neden olduğu (Fazekas ve ark., 2012) belirlenmiştir. Ilgaz ve Çelik (2020), Şiraz üzüm çeşidinde yaprak almanın verimi etkilemediğini; salkım seyreltmenin ise verimi azalttığını ifade etmişlerdir. Cabernet-Sauvignon (Wang ve ark., 2018), Verdejo (Vicente ve Yuste, 2015), Teran (Bubola ve ark., 2017), Pinor Noir (Klon 115) (Mawdsley ve ark., 2019) üzüm çeşitlerinde salkım seyreltme yapıldığında verimin düştüğü tespit edilmiştir. Benzer sonuç U4 (yaprak alma+salkım seyreltme) uygulamasıyla alınmıştır. Ancak bu uygulamadaki (U4) birinci sınıf salkım oranının çok yüksek (\%67.74) olduğu göz ardı edilmemelidir.

Sonuç olarak, salkım özellikleri bakımından, iki üretim sezonunda yaşanan iklimsel farklılıklar; salkım eni, boyu, ağılığı, hacmi, vb. kriterlerini yağışlı sezonda, kurak sezona oranla daha yükseltmiştir. Sofralık üzüm çeşitlerinde salkım eni, salkım ağırlığı, salkım hacmi, salkımdaki tane sayısı ve salkım sıklığı kriterlerinin yüksek olması istenir. Denemede yaprak alma yok + salkım seyreltme (U2) uygulamasının bu değerleri yükselttiği belirlenmiştir. Salkım boyu ile birlikte salkım sıklığı kriteri yaprak alma + salkım seyreltme (U4) uygulamasıyla yükselmiştir. Buradan yola çıkıldığında salkım seyreltme içeren uygulamaların (U2 ve U4) İri Koruk döneminde yapılmasıyla salkım özelliklerinin iyileştirilebileceği sonucuna varılmıştır.

Ayrıca, birinci sınıf salkım oranı 2019 yılında 2018'e nazaran neredeyse bir kat artmıştır. Benzer şekilde 2018 yılında yüksek olan ikinci sınıf salkım oranı 2019 yılında yaklaşık 3 kat azalmıştır. Buradan hareketle yapılmış olan uygulamaların etkilerinin denemenin ikinci yılında salkım sınıflandırmasına katkı sağladığını söylemek mümkündür. Ayrıca uygulamaların dönemleri açısından da TT dönemi ilginç bir şekilde öne çıkmıştır. Kontrol ile karşılaştırıldığında yaprak alma + salkım seyreltme (U4) uygulamasının birinci sınıf salkım oranını artırdığı, ikinci sınıf salkım oranını düşürdüğü görülmüştür. Bu nedenle salkım seyreltme uygulamaları birinci sınıf salkım varlığını artırmada etkili olacağından; üreticiye daha fazla gelir sağlaması olasıdır. Sofralık çeşitlerde verim ve kalite, ürün açısından çok önemlidir. Salkım seyreltme uygulamaları verimde genel olarak düşüşe neden olduğundan; bu uygulamaları yaparken çok dikkatli davranmak gereklidir.

\section{ÖZET}

Amaç: Bu çalışmanın amacı, Michele Palieri/110R aşı kombinasyonuna sahip omcalardan oluşan bağda, yaprak alma ve salkım seyreltme uygulamalarının, salkım özellikleri üzerine etkilerinin belirlenmesidir.

Yöntem ve Bulgular: Deneme 2018-2019 ve 2019-2020 
vejetasyon periyodlarında, Tekirdağ ili Karaevli Mahallesinde, $41^{\circ} 01^{\prime} 11.41^{\prime \prime} \mathrm{K}$ enlem ve $27^{\circ} 39^{\prime} 49.14^{\prime \prime}$ D boylamları arasında, iki yıl süresince yürütülmüştür. Üç uygulama zamanı; Tane Tutumu, İri Koruk, Ben Düşme ile 4 farklı uygulama; Kontrol=U1 (Salkım seyreltme yokYaprak alma yok), U2 (Salkım seyreltme-Yaprak alma yok), U3 (Salkım seyreltme yok-Yaprak alma) ve U4 (Salkım seyreltme-Yaprak alma) yapılmıştır. Salkım özelliklerini ortaya koymak amacıyla: salkım eni-boyu $(\mathrm{cm})$, salkım ağılığı $(\mathrm{g})$, salkım hacmi $\left(\mathrm{cm}^{3}\right)$, salkımdaki tane sayısı (adet), salkım sıklığı ve verim $\left(\mathrm{kg} \mathrm{omca}^{-1}\right)$ belirlenmiştir.

Genel Yorum: Tekirdağ ilinde Michele Palieri üzüm çeşidinde yüksek kalitede üzüm elde edebilmesi için İri Koruk döneminde U2 (Salkım seyreltme-Yaprak alma yok) uygulaması önerilebilir bulunmuştur.

Çalışmanın Önemi ve Etkisi: Elde edilen sonuçlara göre, yapılan salkım seyreltme ve yaprak uygulamalarının Kontrole nazaran verimde $\% 8-48$ arası düşüşe neden olduğu tespit edilmiştir.

Anahtar Kelimeler: Michele Palieri, Yaprak Alma, Salkım Seyreltme, Sofralık Üzüm, Salkım Özellikleri.

\section{ÇIKAR ÇATIŞMA BEYANI}

Makale yazarları aralarında herhangi bir çıkar çatışması olmadığını beyan ederler. Bu çalışma, üçüncü yazar Serhan AZSÖZ'ün yüksek lisans tezinin bir bölümünden üretilmiştir.

\section{ARAŞTIRMACILARIN KATKI ORANI BEYANI}

Yazarlar makaleye eşit oranda katkı sağlamış olduklarını beyan ederler.

\section{KAYNAKLAR}

Bahar E, Korkutal I, Öner H (2018) Cabernet-Sauvignon üzüm çeşidinde farklı kültürel işlemlerin şıra özellikleri üzerine etkileri. Selcuk J. Agric. Food Sci. 32(1): 1-7.

Basile T, Alba V, Gentilesco G, Savino M, Tarricone L (2018) Anthocyanins pattern variation in relation to thinning and girdling in commercial Sugrathirteen ${ }^{\circledR}$ table grape. Sci. Hortic. 227: 202-206.

Bekar T, Cangi R (2018) Narince üzüm çeşidinde verim ve şıra kompozisyonu üzerine salkım seyreltmenin etkileri. Bahçe 47(Özel Sayı): 605-612.

Beslic Z, Todic S, Markovic N, Przic Z (2016) Influence of early basal leaf removal on yield components and must quality on cv. Sauvignon Blanc. Annals of the University of Craiova - Seria Agriculture Montanology Cadastre Series (46): 31-35.
Bogicevic M, Maras V, Mugosa M, Kodzulavic V, Raicevic J, Sucur S, Failla O (2015) The effects of early leaf removal and cluster thinning treatments on berry growth and grape composition in cultivars Vranac and Cabernet Sauvignon. Chem. Biol. Tech. in Agric. 2(13): 1-8.

Bubola M, Sivilotti P, Janjanin D, Poni S (2017) Early leaf removal has a larger effect than cluster thinning on grape phenolic composition in cv. Teran. Am. J. Enol. Vitic. 68: 234-242.

Canon PM, Gonzales Ás, Alcalde JA, Bordeu E (2014) Red wine phenolic compsition: the effects of summer pruning and cluster thinning. Cienc. Investig. Agrar. 41(2): 235-248.

Cantürk S, Kunter B (2018) Beauty Seedless ve Tekirdağ çekirdeksiz üzüm ceşitlerinde ( $V$. vinifera $\mathrm{L}$.) salkım seyreltme ve yaprak almanın antosiyanin birikimi ve kabuk renk özelliklerine etkisi. Bahce 47(1-Özel sayı): 569-574.

Çelik H, Ağaoğlu S, Fidan Y, Marasalı B, Söylemezoğlu G (1998) Genel Bağcılık. Sunfidan A.Ş. Mesleki Kitaplar Serisi:1 Ankara. $253 \mathrm{~s}$.

Dami I, Bordelon B, Ferree DC, Brown M, Ellis MA, Williams RN, Doohan D (2005) Midwest grape production guide. Bulletin 919 Ohio State University Extension USA. 158 p.

Dumartin P, Lemoine B, Marcovelles S (1990) Les travaux en vert de la vigne. Progrèss Agrícole et Viticole 107(6): 143-144.

Fazekas I, Göblyös J, Bisztray GD, Zanathy G (2012) The effect of cluster thinning, cluster tipping, cluster shredding and defoliation at the flowering on the vegetative and generative vine performance from Kékfrankos cv. Int. J. Hortic. Sci. 18(1): 63-68.

Ilgaz F, Çelik M (2020) The effects of applications of leaf removal and cluster thinning on yield and quality of Syrah. Ege Üni. Zir. Fak. Derg. 57(2): 239-247.

Kaya O (2019) Effect of manual leaf removal and its timing on yield, the presence of lateral shoots and cluster characteristics with the grape variety Karaerik. Mitteilungen Klosterneuburg Rebe und Wein Obstbau und Früchteverwertung 69(2): 83-92

Korkutal I, Bahar E, Bayram S (2017) Farklı toprak işleme ve yaprak alma uygulamalarının Syrah üzüm çeşidinde su stresi, salkım ve tane özellikleri üzerine etkileri. Ege Üni. Zir. Fak. Derg. 397-407.

Kotseridis Y, Georgiadou A, Tikos P, Kallithraka S, Koundouras S (2012) Effects of severity of postflowering leaf removal on berry growth and composition of three red Vitis vinifera L. cultivars grown under semiarid conditions. J. Agric. Food Chem. 60(23): 6000-6010. 
Köse B, Çelik H, Çelik D (2018) Determination of the effects of less and excessive leaf removal on cluster characteristics in Trakya ilkeren grape variety. Proceedings of the IX. International Scientific Agriculture Symposium AGROSYM, October 04-07, Jahorina, Bosnia and Herzegovina. pp. 775-781.

Lorenz DH, Eichhorn KW, Bleiholder H, Klose R, Meier U, Weber E (1995) Phenological growth stages of the grapevine (Vitis vinifera L. ssp. vinifera) codes and descriptions according to the extended $\mathrm{BBCH}$ scale. Aust. J. Grape Wine Res. 1: 100-110.

Martins S (2007) Monda de cachos na casta Touriga nacional. efeitos no rendimento e qualidade. Tese Mestrado em Viticultura Oenologia. Universidade Técnica de Lisboa Universidade do Porto, 43 p.

Mawdsley PFW, Peterson JCD, Casassa LF (2019) Multiyear study of the effects of cluster thinning on vine performance, fruit and wine composition of Pinot noir (clone 115) in California's Edna Valley AVA (USA). Sci. Hortic. 256: 108631.

OIV (2009) Organisation Internationale de la Vigne et du Vin $2^{\text {nd }}$ Edition of the OIV Descriptor List for Grape Varieties and Vitis Species. Paris, France. $232 \mathrm{p}$.

Palliotti A, Cartechini A (2000) Cluster thinning effects on yield and grape composition in different grapevine cultivars. Acta Hortic. 512: 111-120.

Pita N (2006) Influência da monda de cachos nas características analíticas de uvas e vinhos da casta Syrah. Relatório de trabalho de fim de curso em Engenharia Agronómica. Universidade Técnico de Lisboa Instituto Superior de Agronomia. $44 \mathrm{p}$.

Reeve AL, Skinkis PA, Vance AJ, McLaughlin KR, Tomasino E, Lee J, Tarara JM (2018) Vineyard floor management and cluster thinning inconsistently affect Pinot noir crop load, berry composition, and wine quality. HortSci. 53(3): 318-328.

Reynolds A, Price S, Wardle D, Watson B (1994) Fruit environment and crop level effects on Pinot noir. Vine performance and fruit composition in the British Columbia. Am. J. Enol. Vitic. 45: 452-459.
Smithyman RP, Howell GS, Miller DP (1998) The use of competition for carbohydrates among vegetative and reproductive sinks to reduce fruit set and Botrytis bunch rot in Seyval Blanc grapevines. Am. J. Enol. Vitic. 49: 163-170.

Smart RE, Gravett IM, Fisher BM (1990) Canopy management to improve grape yield and wine quality-principles and practices. S. Afr. J. Enol. Vitic. 23(23): 23-17

Smart RE, Robinson M (2006) Sunlight into Wine - A Handbook for Winegrape Canopy Management. Winetitles Adelaide, Australia. $88 \mathrm{p}$.

TMM (2019) Tekirdağ il Meteoroloji Müdürlüğü Kayıtları. Tekirdağ

Verdenal T, Zufferey V, Spring JL, Rösti J, Dienes-Nagy A, Lorenzini F, Viret $O$ (2016) Pros and cons of early defoliation of the white cv. Vitis vinifera Doral in the Leman region (Switzerland). Rev. Suisse Vitic. Arboric. Hortic. 48(3): 176-182.

Vicente A, Yuste J (2015) Cluster thinning in cv. Verdejo rainfed grown: Physiologic, agronomic and qualitative effects, in the D.O. Rueda (Spain). BIO Web of Conferences, 5: 01020.

Vogel AR, White RS, MacAllister C, Hickey CC (2020) Fruit zone leaf removal timing and extent alters bunch rot, primary fruit composition, and crop yield in Georgiagrown Chardonnay (Vitis vinifera L.). HortSci. 55(10): 1654-1661.

Wang Y, He YN, Chen WK, He F, Chen W, Cai XD, Duan $C Q$, Wang J (2018) Effects of cluster thinning on vine photosynthesis, berry ripeness and flavonoid composition of Cabernet-Sauvignon. Food Chem. 248: 101-110. 